\title{
The dangers of leaving home: dispersal and mortality in snakes
}

\author{
Xavier Bonnet ${ }^{\mathrm{a}, \mathrm{b}, 1}$, Guy Naulleau ${ }^{\mathrm{a}}$, Richard Shine ${ }^{\mathrm{b}, *}$ \\ ${ }^{a}$ Centre d'études biologiques de Chizé, CNRS, 79360 Villiers en Bois, France \\ ${ }^{\mathrm{b}}$ School of Biological Sciences A08, University of Sydney, NSW, Australia
}

Received 25 August 1998; accepted 6 October 1998

\begin{abstract}
For animal populations in many parts of the world, direct (albeit often accidental) killing by humans may be a significant source of mortality. Many snakes are killed by people (especially by automobiles) every year, but the determinants of a snake's vulnerability to anthropogenic mortality (and thus, patterns of mortality with respect to sex, age and season) are poorly known. We present data on 652 French snakes of six species (Coluber viridiflavus, Elaphe longissima, Natrix maura, N. natrix, Vipera aspis, V. berus) killed either by natural predators, domestic animals or humans (including roadkills). We used information on seasonal patterns of mortality (plus information on population structure from 338 captures of live snakes) to test the hypothesis that snakes are killed mostly when they disperse from their usual home ranges. This hypothesis generates several falsifiable predictions on the expected correlates of mortality rates; most of these predictions are supported by our data. For example, young-of-the-year snakes are killed primarily in the period immediately after hatching (while they disperse); subadults (which are sedentary) generally experience low mortality rates; adult males are killed mainly during the mating season (especially in species where mate-searching males travel widely); and adult females in oviparous species are killed during their egg-laying migrations. Relative to population density, species that use frequent long-distance movements in foraging experience higher mortality than sedentary ambush foragers. In one species (E. longissima), larger males are more at risk. The success of these predictions suggests that movement patterns of snakes may offer valuable indices of their vulnerability to direct anthropogenic mortality. (C) 1999 Elsevier Science Ltd. All rights reserved.
\end{abstract}

Keywords: Demography; Costs of reproduction; Reptile; Snake; Survival

\section{Introduction}

Human activities can threaten the viability of animal populations through a variety of processes, some of them complex (e.g. subtle modifications of habitat structure) and some of them very straightforward (e.g. over-harvesting). For many animal populations living in densely-settled areas, direct killing by humans may be a significant component of the overall effect of human activities on wild populations. Because this aspect of the interaction between humans and wildlife is unlikely to be as important overall as broader-scale processes such as habitat destruction (e.g. Dodd, 1987; Caughley and Sinclair, 1994), direct killing of wildlife has tended to attract more attention from community-based "conservation" organisations than from professional scientists.

\footnotetext{
* Corresponding author. Tel.: +61-2-9351-3772; fax: +61-2-93515609; e-mail: rics@bio.usyd.edu.au

1 Tel.: +33-549-096-111; bonnet@cebc.cnrs.fr
}

The impact of this kind of direct killing on natural populations is difficult to evaluate, because the degree to which anthropogenic mortality affects population viability depends on a complex series of factors. The absolute number of animals killed is obviously important, but population-level impacts will also depend on the kinds of animals killed (e.g. male vs female, adult vs juvenile, reproductive vs non-reproductive) as well as the timing of mortality (e.g. before or after reproductive activities; whether or not the additional mortality coincides with seasons of nutritional stress: Caughley and Sinclair, 1994). In practice, we have little clear understanding of the patterns of direct anthropogenic mortality on most kinds of wild populations (e.g. Burbidge and Jenkins, 1984), or even of the underlying motivation for such destruction. Killing of wildlife can be motivated by factors such as commercial gain (Fitzgerald et al., 1991; Warwick et al., 1991), hunger (Klemens and Thorbjarnarson, 1995) or fear (Dodd, 1993), but much of it is accidental. For example, highway mortality is common in many areas (Ehmann and Cogger, 
1985; Mittermeier et al., 1992; Rosen and Lowe, 1994), and drivers may often be unaware of the presence of the animals that they kill. Malicious killing is likely to be particularly important for a subset of animal species that arouse fear and resentment from the general public. Snakes feature high on this list, with many reports of intentional killing (e.g. Brown, 1993; Seigel, 1986). Indeed, a review on threatening processes important for snake conservation identified malicious killing as a significant issue (Dodd, 1987).

Before we can evaluate the impact of direct killing on natural populations, the first step is to document the patterns of mortality that result from such killing. Such data may provide a useful basis for recommendations directed to the particular systems in which the studies have been conducted (e.g. Fitzgerald et al., 1991, 1993). Unfortunately, it may be difficult to generalise such results to other systems (areas, species) unless we can also gain an understanding of the processes involved in determining vulnerability of an animal to anthropogenic sources of mortality. Thus, we ideally need not only to quantify the relative degree of risk experienced by different species, and by different sex/age classes within each species, but we also need to identify the reasons why particular taxa and/or particular segments of the population are at higher risk. Only with this level of understanding can we begin to extrapolate results from one system to other areas and taxa.

In the present paper, we describe the results of such a study on patterns of anthropogenic mortality (direct killing) in six species (four genera) of European snakes. Snakes are killed by many different types of "predators", but by far the most obvious (and thus, easily quantified) source of mortality is the risk of being run over by an automobile. Our data set includes this type of mortality, enabling us to compare general patterns in mortality rates between the victims of "natural" predators vs "roadkills". Having noted broad similarities, we then use the combined data set to explore predictions from a specific hypothesis on the determinants of vulnerability to predation.

This hypothesis is as follows. We suggest that the prime determinant of "risk" is movement-and in particular, dispersal away from the usual home range. Although snakes may be at risk in the course of many other activities (e.g. basking, foraging, mating: Gibbons and Semlitsch, 1987; Gregory et al., 1987), we suspect that their vulnerability is far greater during extensive movement. We base this hypothesis not only on our own experience in working with snakes over many years, but also from published literature suggesting that sedentary snakes are relatively invulnerable to predation whereas moving snakes are at high risk (e.g. Gregory and Stewart, 1975; Slip, 1986; Shine, 1993; Rosen and Lowe, 1994; Aldridge and Brown, 1995; Shine and Fitzgerald, 1995).

\section{Methods}

In this paper, we use data gathered on snakes that we found after they had been killed by various "predators", including birds, native carnivorous mammals, domestic pets (cats, dogs) and people. We have not attempted to separate these agents into "natural" vs "anthropogenic" sources of mortality, because of the complex way in which human activities may modify opportunities for "natural" predators. For example, common buzzards (Buteo buteo) often feed on snakes (Naulleau et al., 1997), and provided most of the records of bird predation. Although these birds are "natural" predators, their ability to locate snakes is undoubtedly modified by anthropogenic changes to habitat structures (e.g. snakes are more exposed in agricultural fields and roads than in undisturbed forests). "Predation" by humans occurred mostly in the form of roadkills, but some snakes were deliberately attacked and killed away from roads. Carcasses are removed fairly rapidly by scavengers, so that most of the snakes we collected had probably been killed quite recently $(<24 \mathrm{~h})$. The source of mortality was inferred from the snake's location (e.g. on a road, or in a dog's mouth) and the nature of the damage to the snake's body.

\subsection{Species studied}

We obtained information on six sympatric snake species belonging to four genera and two families (Viperidae and Colubridae). Although all of these species are still common in the study area, the same taxa have shown substantial declines in other parts of their range (Gruschwitz et al., 1993), including parts of France (Castanet and Guyetant, 1989; Gasc et al., 1997). The main ecological characteristics of these taxa are summarised in Table 1. The six species differ in body sizes, body shapes, activity patterns, seasonal activity schedules, food habits, sexual dimorphism, reproductive mode, and in the extent of their dependence on stored energy for reproduction (Table 1). Because snakes exhibit strong phylogenetic conservatism in traits such as sexual size dimorphism, mating systems and reproductive mode (Shine, 1994; and see Table 1), we pooled the six species into four genera for statistical analyses.

\subsection{Sampling method}

\subsubsection{Dead snakes}

Specimens were collected in various part of France, but $>97 \%$ were found in Western Central France, in six districts close to our laboratory (Deux-Sèvres, Charente, Charente Maritime, Vendée, Vienne, and Loire Atlantique). More than $90 \%$ of the total were collected in Deux-Sèvres and Charente Maritime (our laboratory is situated in the Forest of Chizé, near the boundary between these two districts). 
Table 1

Main ecological characteristics for four snake genera (six species) in western central France ${ }^{\mathrm{a}}$

\begin{tabular}{|c|c|c|c|c|c|c|}
\hline Genus & Vivera & & Natrix & & Elaphe & Coluber \\
\hline Species & aspis & berus & natrix & maura & longissima & viridiflavus \\
\hline Common name & Aspic viper & Adder & Grass snake & Viperine snake & Esculapian snake & Whip snake \\
\hline Reproductive mode & Viviparous & Viviparous & Oviparous & Oviparous & Oviparous & Oviparous \\
\hline Reproductive strategy & Capital $^{\mathrm{b}}$ & Capital & Capital & Capital & Income $^{\mathrm{b}}$ & Intermediate \\
\hline Foraging mode & Sit and wait & Sit and wait & Sit and wait & Sit and wait & Active & Active \\
\hline Main prey types & Voles & Voles & Amphibians & Fishes & Mammals-birds & Mammals-lizards \\
\hline Activity season ${ }^{\mathrm{c}}$ & March-October & March-October & April-October & March-October & April-October & April-October \\
\hline \multicolumn{7}{|c|}{ Mean snout-vent length $(\mathrm{cm})$} \\
\hline Adult males & $48.1 \pm 4.3$ & $48.0 \pm 4.9$ & $54.1 \pm 3.3$ & $37.0 \pm 5.0$ & $92.36 \pm 14.66$ & $92.71 \pm 8.52$ \\
\hline Adult females & $48.9 \pm 3.7$ & $52.7 \pm 4.1$ & $79.5 \pm 8.2$ & $47.7 \pm 5.3$ & $82.72 \pm 7.23$ & $84.2 \pm 9.55$ \\
\hline Larger (heavier) sex & Female & Female & Female & Female & Male & Male \\
\hline Population densities & Very high & High & High & $?$ & High & High \\
\hline
\end{tabular}

a References: Saint Girons, 1957, 1975, 1986; Naulleau, 1965, 1989, 1992; Duguy and Saint Girons, 1966; Madsen, 1984, 1987; Hailey and Davies, 1986a,b; Castanet and Guyetant, 1989; Ciofi and Chelazzi, 1991; Madsen and Shine, 1992, 1993, 1994; Eckstein, 1993; Forsmann, 1995; Naulleau and Bonnet, 1995; Bonnet and Naulleau, 1996a,b; Gasc et al., 1997; Luiselli et al., 1997.

b The terms "capital" vs "income" breeder refer to alternative sources (body reserves vs recently gathered prey) of energy used to fuel reproduction.

c Activity season and population status apply to the studied zone only.

\subsubsection{Live snakes}

In order to test predictions concerning the relative vulnerability of different age/sex classes to "predation", we need to compare the numbers killed to the numbers present in that category overall. For example, we need to know what proportion of the population is composed of subadults, before we can determine whether the proportion of subadults among the "predated" snakes is higher than would be expected under the null hypothesis of equal vulnerability to predation in all age classes. This requirement raises a logistical problem: it is difficult to determine the exact composition of the population, because all methods of capturing individuals will introduce certain biases. In the absence of extensive mark-recapture studies to overcome this problem, we have chosen to compare the "predated" individuals with large samples of living snakes of the same species collected under shelter items (concrete slabs) in the forest of Chizé since 1994. These slabs are checked regularly, and any snakes beneath them are captured, measured, marked and released. Because the sample does not rely on activity by the snakes to render them vulnerable to collection, it may provide a reasonably accurate representation of the relative numbers of snakes of each size and sex within the population.

\subsection{Measurements}

For each specimen, species and gender were determined. Exact time, location, total and snout-vent length (SVL), along with total body mass were also recorded. Snakes were classified into three categories based on their snout-vent length, in combination with published and unpublished information on growth curves, and sizes at sexual maturation within each species (from references in Table 1, especially Saint Girons, 1975; Naulleau and Saint Girons, 1981; and pers. obs):

1. neonates, whose SVL indicates that they are $<12$ months of age;

2. subadults, with SVLs under minimal size for sexual maturity, broadly 1 to 4 years of age;

3. adults, SVL equal or greater than size at sexual maturity, generally 3 to 10 years of age.

Prey items found in the digestive tract were removed before the snake was weighed. For some badly-damaged specimens (especially road-killed neonates), a number of characteristics (e.g. sex, length, mass) could not be recorded.

\subsection{Comparisons of mortality rates among seasons}

Our statistical analyses were restricted to data gathered during the general activity periods for each species, excluding hibernation: broadly from April to October. However, none of our major results were modified when the hibernation period was included. Mating seasons, vitellogenesis, laying periods, and birth periods for snakes in western Central France were obtained from published studies and from our unpublished data (Saint Girons, 1957; Duguy and Saint Girons, 1966; Naulleau, 1989; Bonnet et al., 1994; Bonnet and Naulleau, 1996a; Vacher, 1997). Based on these results, we divided the data for each sex/age class of each species into biologically meaningful time periods corresponding to the seasonal occurrence of mating, gestation (in viviparous forms), egg-laying and parturition, and the post-hatching period. These periods were as follows. For neonates/ 
hatchlings, we divided the active season into three periods: hatching/birth (mid-August to September for all the 4 genera), pre-hatching/birth (April to mid-August) and post-hatching/birth (October). For subadults, such categories would be meaningless (because they do not have particular seasonal activities), and thus we simply use monthly periods for comparisons. For adult males, we used three periods corresponding to pre-mating (April to mid-May for both Coluber and Elaphe; none for Natrix and Vipera because they mate soon after spring emergence), mating (mid-May to mid-June for Coluber, mid-May to late June for Elaphe; mid-March to April for Natrix, March-April for Vipera), and postmating (mid-June to October for Coluber, July to October for Elaphe; mid-May to October for both Natrix and Vipera). For adult oviparous females, the relevant periods were defined as before vitellogenesis (April for both Coluber and Elaphe; mid-April to the end of April for Natrix), vitellogenesis period (May to mid-June for Coluber, May-June for Elaphe, and mid-April to midJune for Natrix), laying (mid-June-mid-July for both Coluber and Natrix, July to early August for Elaphe), and post-laying (July-October for Coluber and Natrix, mid-August-October for Elaphe). For adult females of the viviparous Vipera, we used three periods corresponding to vitellogenesis (March to mid-June), gestation (mid-June to mid-August), and post-parturition (mid-August to October).

All statistical analyses were performed using Statistica 5.1, Statview 4.5 and SuperAnova 1.11 computer packages. Yates correction was applied for all appropriate analyses with low sample sizes.

\subsection{Predictions from the "vulnerability during dispersal" hypothesis}

If snakes are most at risk when they disperse from their usual home range, we expect to see clear patterns in the rates of mortality that these animals experience (Table 2). Mortality rates should be highest in those groups that move about most widely; specifically, neonates/hatchlings immediately after birth/hatching; adult males during the mating season (at least in species in which mate-searching involves significant travel, because reproductive females are widely dispersed); and adult females of oviparous species at the time of their egg-laying migrations. Because most other age/sex classes are relatively sedentary, we would expect mortality to be relatively low. For example, the species that we studied do not undergo long migrations from overwinter sites to summer home ranges, unlike the situation in colder areas where suitable hibernacula may be scarce and widely separated (e.g. Gregory et al., 1987). We can also generate predictions about sex differences in mortality rates in adults: because males move around more than females, and for a longer time period (see references in Table 1), we would expect males to experience higher mortality. Interspecific comparisons are also of interest: we would expect that highly mobile wide-ranging species (such as Coluber viridiflavus) would experience higher mortality overall than would a sedentary taxon such as Vipera aspis.

\subsection{Results}

Since 1968, we collected a total of 652 "predator"killed snakes. Most of them were collected recently, from 1990 to 1998 ( $n=597 ; 92 \%$ of the total). Roadkills $(n=454)$ comprised $70 \%$ of the sample. Our data on live snakes (collected under concrete slabs in the forest) are based on 338 individuals.

Before we test the predictions outlined above, we compare general patterns of mortality in snakes killed by predators vs those killed by automobiles. The comparison is interesting in its own right, and also because a similarity in the general patterns would suggest that the determinants of mortality due to roadkills may provide insight into the factors generating "natural" sources of mortality. We can compare the roadkills to predator kills in two respects:

1. The seasonality of mortality rates. During the activity period, the occurrence of accidental mortality varied greatly among months $\left(\chi^{2}=281.59\right.$, $\mathrm{df}=6, p<0.0001)$. The monthly variation in rates of roadkill mortality and predator deaths showed very similar patterns. These two rates were highly correlated, regardless of whether the analysis

Table 2

Predictions from the hypothesis that movement (especially, movement away from the usual home range) is the prime determinant of mortality risk (vulnerability to "predators", including automobiles) for snakes

\begin{tabular}{lll}
\hline Age/sex class & Predicted magnitude of risk ${ }^{\mathrm{a}}$ & Predicted seasons of highest risk \\
\hline Neonates/hatchlings & High & Hatching and post-hatching period \\
Subadults & Low & No seasonality \\
Adult males & High & Mating period \\
$\begin{array}{l}\text { Adult females } \\
\text { (i) oviparous species }\end{array}$ & High & Egg-laying period \\
(ii) viviparous species & Low? & No seasonality \\
\hline
\end{tabular}

${ }^{\text {a }}$ Predictions concern the period of the year when snakes are active (i.e. out of hibernation). 
was based on all snakes (Spearman's Rank Correlation, $\mathrm{rs}=0.75, N=7, p=0.05$ ), or on adults only (rs $=0.82, N=7, p<0.024$; Fig. 1 ).

2. the relative rates of mortality across species and age/sex classes. To compare the two samples in this respect, we plotted the numbers of individuals in each category of roadkills against the numbers in each category for predator kills. Although the scatter is wide, the resulting graph confirms a significant degree of similarity in the overall proportions of different species/sex/age classes making up the two samples ( $\mathrm{rs}=0.55, N=16, p=0.026$; Fig. 1 ).

We now turn to predictions from the "dispersal vulnerability" hypothesis, and evaluate the degree to which this idea is able to predict general patterns in mortality rates. Given the broad similarity in patterns of mortality among the roadkill sample and the predator-kill sample (above, and see Fig. 1), we combine these two data sets for this analysis. For the comparisons involving the seasonal timing of predation, our analyses take into account the relative duration of time in each of the relevant periods. Table 3 provides a list of the numbers of each/sex class in each genus in each biologicallydefined period.

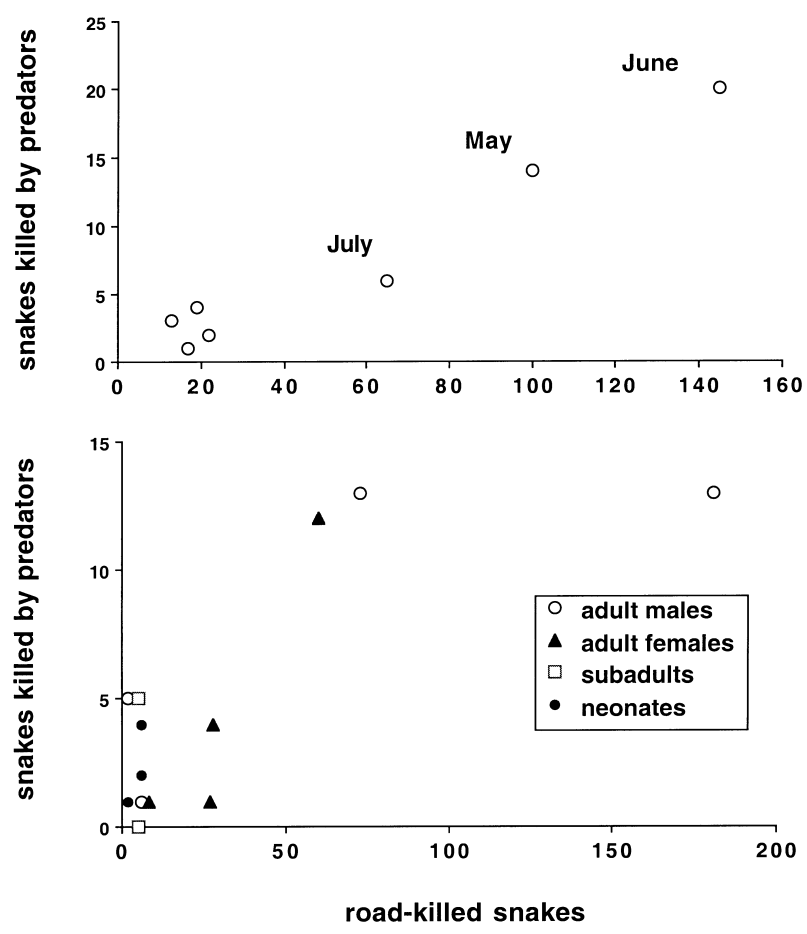

Fig. 1. A comparison between two samples of dead snakes collected in western central France. One sample was of snakes killed by "natural" predators (see text for definitions) whereas the other group was killed by automobiles. Data from the overwinter (hibernation) period were excluded, so that all data come from the active period (April to October). The two samples show similar patterns in terms of (A) seasonality of mortality rates (all snakes combined), and (B) relative mortality rates of each genus, and age/sex classes within those taxa.
2.6.1. Prediction 1: neonates and hatchlings experience high mortality rates

This prediction suggests that the proportion of neonates should be higher among the predated snakes than among live snakes. Data in Table 4 support this prediction overall (combining all species, relative numbers of live vs dead in neonates vs others: $\chi^{2}=41.16,1 \mathrm{df}$, $p<0.001)$. The same trend was evident in each of the genera when they were considered separately (see Table 4 ), and was statistically significant within two of these genera (Natrix and Coluber, Table 4).

\subsubsection{Prediction 2: mortality of neonates and hatchlings occurs mostly in the period immediately after birth or hatching}

Fig. 2 provides strong support for this prediction overall, with a pronounced peak in the number of neonates killed in the hatching period. Combining data for all species, the contingency-table test yields a highly significant result $\left(\chi^{2}=161.7,2 \mathrm{df}, p<0.0001\right.$ using the three biologically-defined periods, and $\chi^{2}=691.5,6 \mathrm{df}$, $<0.0001$ using months as time intervals). The same pattern is evident within three of the genera, with mortality higher in this period than at other times of year (against a null hypothesis of equal mortality rates per unit time: Coluber $-\chi^{2}=171.7,2$ df, $p<0.001$; Natrix- $\chi^{2}=8.4,2 \mathrm{df}, p=0.015$ using biologicallydefined periods; and Coluber- $\chi^{2}=568.4,6 \mathrm{df}$, $p<0.001$; Elaphe - $\chi^{2}=30.8,6 \mathrm{df}, p<0.001$; Natrix$\chi^{2}=24.4,5 \mathrm{df}, p=0.015$ when using months as time intervals). One problem with these tests is that the numbers of neonates are also highest at this time, before the mortality occurs. Thus, the numbers killed may reflect the numbers present rather than a disproportionate risk. We can evaluate this possibility using the data-set on live snakes. The "dispersal vulnerability" hypothesis predicts that the numbers of neonates killed relative to the number of live neonates recorded should be higher in the hatching period than at other times of the year. Contingency-table analysis supports this prediction for Coluber $\left(\chi^{2}=52.9,2 \mathrm{df}, p<0.001\right)$ and Elaphe $\left(\chi^{2}=14.11,2 \mathrm{df}, p<0.01\right)$; the same trend occurs in Natrix, but sample sizes were too low for statistical testing (see Table 4).

Because we measured the body sizes of all of the animals sampled, we can also use this information to test the prediction in a different way. If mortality of neonates/hatchlings is concentrated in the period soon after hatching/birth, then the mean body size of "predated" offspring is likely to be smaller than that of living offspring (because at least some of the latter group have had significant time to grow since hatching). A one-factor ANOVA comparing live vs dead hatchlings supports this prediction for Coluber viridiflavus (mean SVL for live $=27.5 \mathrm{~cm}$, for $\operatorname{dead}=25.7 \mathrm{~cm} ; F_{1,58}=7.93$, $p<0.01)$. The same trend occurs, but does not attain 
statistical significance, in Elaphe longissima (mean SVL for live $=25.5 \mathrm{~cm}$, for dead $=25.1 \mathrm{~cm} ; F_{1,20}=0.23$, $p=0.64)$. Sample sizes for the other species are too low for statistical testing.

\subsubsection{Prediction 3: mortality rates of subadults are low}

As predicted, subadult snakes are killed only rarely (Fig. 2), but are frequently found alive. Analysis of the total data reveals that the relative numbers of dead vs live snakes were much lower for subadults than for the other age classes combined $\left(\chi^{2}=233.0,1 \mathrm{df}\right.$, $p<0.001)$. The same pattern is evident when the data for each genus are examined separately. These comparisons are statistically significant for the three genera with largest sample sizes (Table 5).
2.6.4. Prediction 4: mortality rates of subadults, show no clear seasonality

Because subadults are rarely killed, we cannot examine this pattern statistically. However, inspection of the data suggests that there is no clear seasonal peak in mortality rates of these animals (Fig. 2).

\subsubsection{Prediction 5: adult males experience relatively high mortality}

In order to test this prediction, we need to specify the group to which adult males are to be compared. There are two plausible choices in this respect. First, we can compare the relative numbers of live vs dead adult males, to the numbers of live vs dead specimens in all of the other age/sex classes combined. Analysis of the

Table 3

Numbers of dead snakes in each sex/age class in each genus in each biologically-defined time period (4 for the females, 3 for the other groups, see text) $)^{\mathrm{a}}$

\begin{tabular}{|c|c|c|c|c|c|}
\hline Periods & & 1 & 2 & 3 & 4 \\
\hline Adult males & & Pre-mating & Mating & Post-mating & \\
\hline \multirow[t]{2}{*}{ Adult females } & Oviparous & Pre-vitellogenic & Vitellogenic & Laying & Post-laying \\
\hline & Viviparous & Vitellogenic & Gestation & Postpartum & \\
\hline Subadults & & April-May & June-July & August-October & \\
\hline Neonates & & Pre-hatching & Hatching & Post-hatching & \\
\hline \multirow[t]{4}{*}{ Coluber } & Adult males & 16 & 109 & 66 & - \\
\hline & Adult females & 6 & 22 & 29 & 18 \\
\hline & Subadults & 5 & 2 & 3 & - \\
\hline & Hatchlings & 12 & 113 & 4 & - \\
\hline \multirow[t]{4}{*}{ Elaphe } & Adult males & 10 & 61 & 14 & - \\
\hline & Adult females & 1 & 15 & 14 & 2 \\
\hline & Subadults & 1 & 1 & 3 & - \\
\hline & Hatchlings & 6 & 10 & 5 & - \\
\hline \multirow[t]{4}{*}{ Natrix } & Adult males & 0 & 1 & 6 & - \\
\hline & Adult females & 0 & 9 & 14 & 4 \\
\hline & Subadults & 0 & 2 & 3 & - \\
\hline & Hatchlings & 7 & 9 & 0 & - \\
\hline \multirow[t]{4}{*}{ Vivera } & Adult males & 0 & 1 & 8 & - \\
\hline & Adult females & 0 & 3 & 0 & 2 \\
\hline & Subadults & 1 & 2 & 2 & - \\
\hline & Neonates & 3 & $\mathbf{0}$ & 0 & - \\
\hline
\end{tabular}

a The time periods for which we predict the highest mortality rates (based on the "dispersal vulnerability" hypothesis) are indicated in boldface. For subadults, we simply divided the 7-month activity period into three broadly equal parts; see text for explanation. Note that "risky" periods are generally briefer (1-2 months in duration) than the other periods (4-5 months).

Table 4

Comparisons between the relative numbers of neonatal snakes accidentally killed vs captured alive (sheltering under slabs) relative to the numbers in other age/classes (i.e. subadults plus adults) in four snake genera

\begin{tabular}{|c|c|c|c|c|c|c|c|}
\hline Genus & Type & Neonates & Others & $\%$ & $\chi^{2}$ & d.f. & $p$ \\
\hline \multirow[t]{2}{*}{ Coluber } & Killed & 129 & 286 & 31 & 15.59 & 1 & 0.0001 \\
\hline & Live & 13 & 114 & 10 & & & \\
\hline \multirow[t]{2}{*}{ Elaphe } & Killed & 23 & 125 & 16 & 1.72 & 1 & 0.189 \\
\hline & Live & 16 & 137 & 11 & & & \\
\hline \multirow[t]{2}{*}{ Natrix } & Killed & 16 & 43 & 27 & 13.25 & 1 & 0.003 \\
\hline & Live & 0 & 48 & 0 & & & \\
\hline \multirow{2}{*}{ Vipera } & Killed & 3 & 21 & 13 & 0.00 & 1 & 0.975 \\
\hline & Live & 2 & 8 & 20 & & & \\
\hline
\end{tabular}


combined data set supports this prediction $\left(\chi^{2}=66.7,1\right.$ $\mathrm{df}, p<0.001$ ). The same conclusion holds true for three of the four genera for which we have sufficiently large samples for quantitative testing (Coluber $-\chi^{2}=15.3,1$ $\mathrm{df}, p<0.001$; Elaphe - $\chi^{2} 21.6,1 \mathrm{df}, p<0.001$; Natrix$\chi^{2}=1.39,1 \mathrm{df}, p=0.24 ;$ Vipera- $\chi^{2}=3.96,1 \mathrm{df}$, $p<0.05)$. Second, we can compare the relative mortality rates (number killed compared to number caught alive) between adult males and congeneric adult females (i.e. sex ratios of adults in the two samples). The results are similar to those obtained above, with statistically significant support from the combined data set $\left(\chi^{2}=30.4,1 \mathrm{df}, p<0.001\right)$ as well as from two of the generic-level analyses (Coluber- $\chi^{2}=17.8,1 \mathrm{df}, p<0.001$; Elaphe $-\chi^{2}=12.5,1 \mathrm{df}, p<0.001$; Natrix- $\chi^{2}=0.21$, $1 \mathrm{df}, p=0.65$; Vipera- $\chi^{2}=2.89,1 \mathrm{df}, p=0.09$ ).

\subsubsection{Prediction 6: adult males are killed mainly during the mating season}

This prediction is strongly supported; there is a marked peak in mortality of adult males at this time of year (Fig. 3). Contingency-table tests support the prediction overall $\left(\chi^{2}=110.1,2 \mathrm{df}, p<0.001\right)$, and also within Coluber $\left(\chi^{2}=68.4,2 \mathrm{df}, p<0.001\right)$ and Elaphe $\left(\chi^{2}=56.8,2 \mathrm{df}, p<0.001\right)$. The same conclusion is reached using months as time intervals overall $\left(\chi^{2}=295.3,6\right.$ df, $\left.p<0.001\right)$, and within Coluber $\left(\chi^{2}=197.4,6 \mathrm{df}, p<0.001\right)$ and Elaphe $\left(\chi^{2}=138.3,6\right.$ df, $p<0.001)$.

\subsubsection{Prediction 7: adult females of oviparous species} experience high mortality rates during the egg-laying period

We can test this prediction in two ways. First, the number of oviparous females killed at this time of year is much greater (per unit time) than at any other period (Fig. 3; for the combined data set, $\chi^{2}=44.8,3 \mathrm{df}$, $p<0.001$; for Coluber $-\chi^{2}=14.9,3 \mathrm{df}, p<0.001$; Elaphe $-\chi^{2}=45.6,3 \mathrm{df}, p<0.001 ;$ Natrix $-\chi^{2}=16.4,3$ df, $p<0.001)$. Second, the relative number of dead versus live adult females was much higher in this period than at other times (for the combined data set,

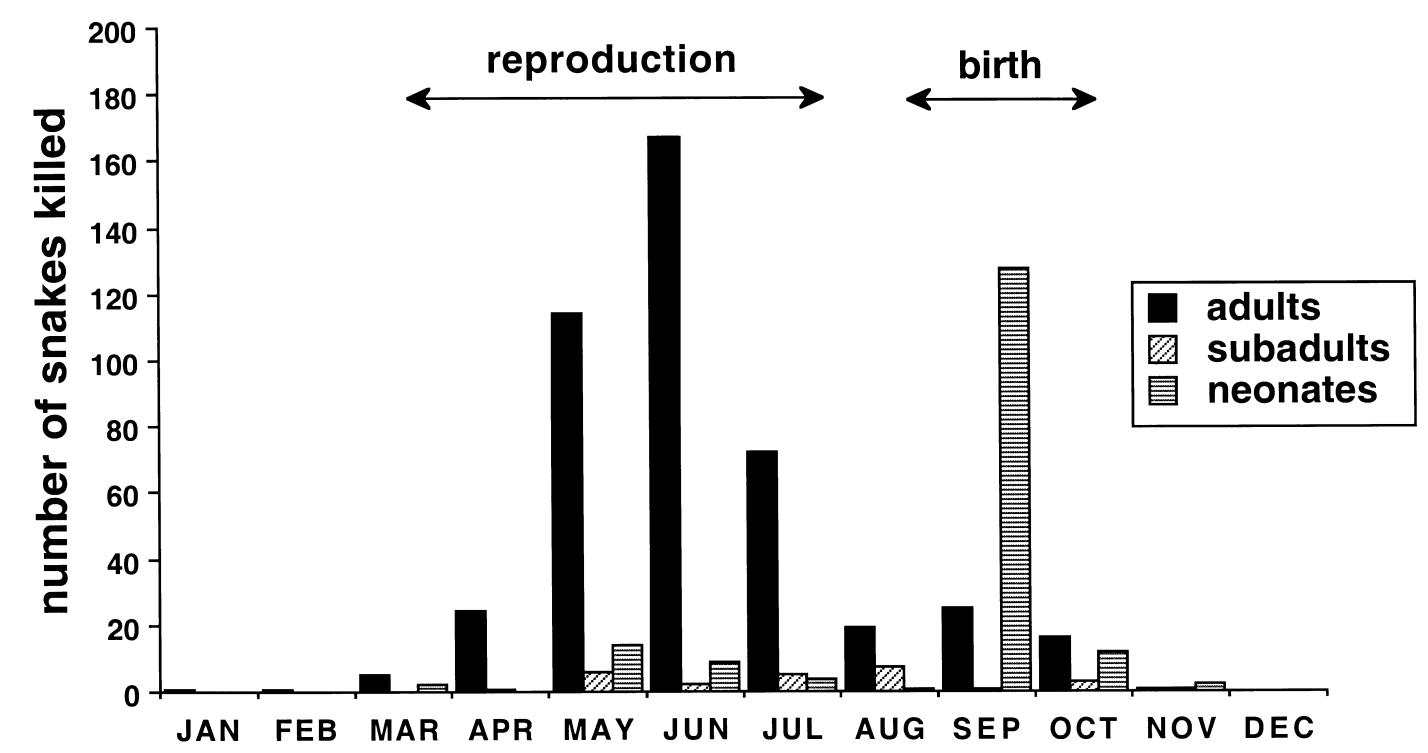

Fig. 2. The seasonal (monthly) distribution of accidental mortality rates in three age classes of snakes. See text for definitions of adults, subadults, and neonates. Reproduction broadly encompasses mating, vitellogenesis, and laying periods. Births broadly encompass parturition and hatchling periods. Data for all four genera (six species - see text) are pooled for this figure.

Table 5

Comparisons between the relative numbers of subadult snakes accidentally killed vs captured alive (sheltering under slabs) relative to the numbers of other age/sex classes (i.e. neonates plus adults) in four snake genera

\begin{tabular}{|c|c|c|c|c|c|c|}
\hline Genus & Type & Subadults & Others & $\chi^{2}$ & d.f. & $p$ \\
\hline \multirow[t]{2}{*}{ Coluber } & Killed & 10 & 405 & 173.79 & 1 & 0.0001 \\
\hline & Live & 60 & 67 & & & \\
\hline \multirow[t]{2}{*}{ Elaphe } & Killed & 6 & 142 & 35.62 & 1 & 0.0001 \\
\hline & Live & 46 & 107 & & & \\
\hline \multirow[t]{2}{*}{ Natrix } & Killed & 5 & 54 & 46.95 & 1 & 0.0001 \\
\hline & Live & 35 & 13 & & & \\
\hline \multirow[t]{2}{*}{ Vipera } & Killed & 5 & 19 & 0.02 & 1 & 0.896 \\
\hline & Live & 3 & 7 & & & \\
\hline
\end{tabular}



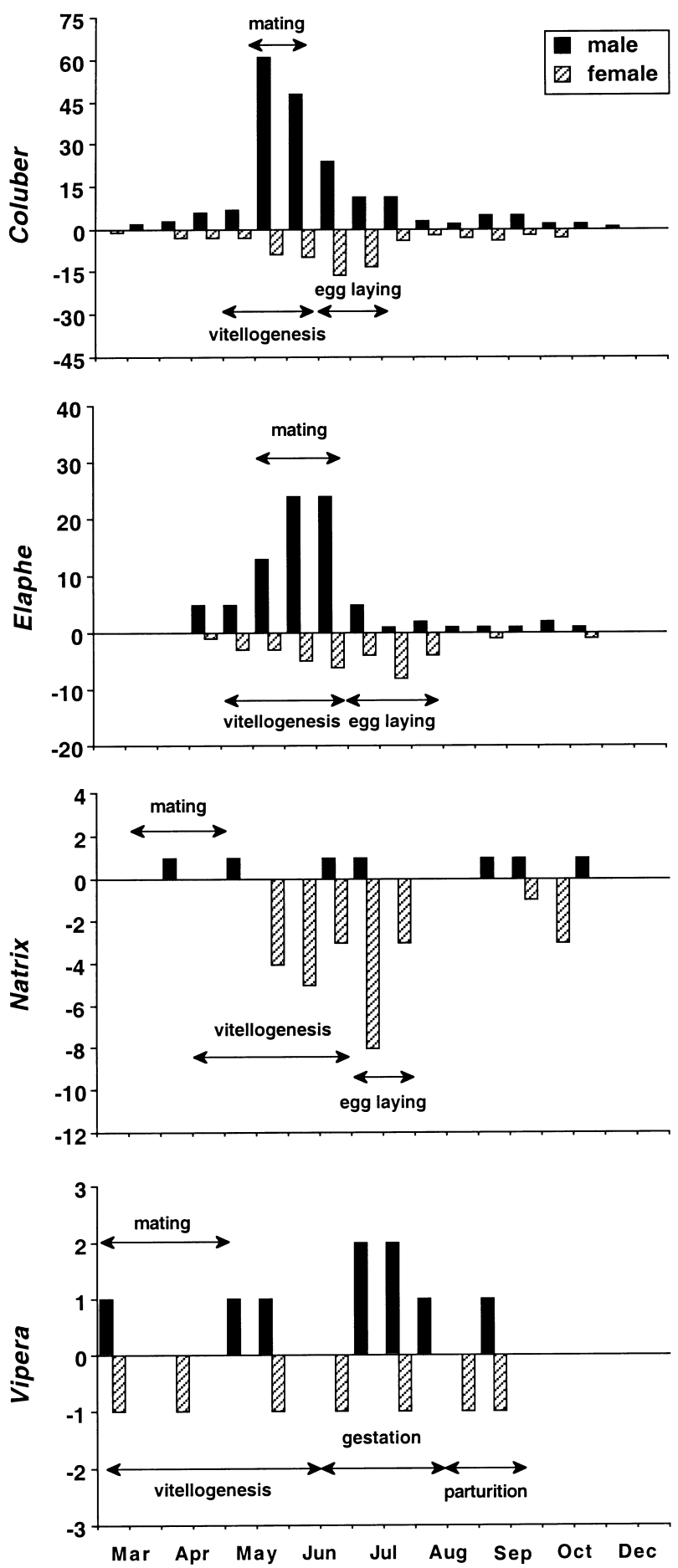

Fig. 3. The seasonal distribution of accidental mortality rates in adult snakes of four genera, in relation to biologically meaningful periods. For each species, the duration of each period was determined using published and unpublished information recorded in western central France since 1950 (see Refs. in Table 1 footnotes). The mating period was defined as the interval between the first and the last mating observed in the field. Vitellogenesis was defined as the interval from the beginning of follicular growth to the end of ovulation $(\bigcirc)$. The laying period was defined as beginning at ovulation, and concluding with the latest recorded date of oviposition. The parturition period covered the interval from the first to the last record in the field. $\left.\chi^{2}=14.3,3 \mathrm{df}, p<0.003\right)$, although sample sizes for the individual genera were too low for statistical significance (Coluber- $\chi^{2}=5.2,3 \mathrm{df}, p=0.16$; Elaphe$\chi^{2}=4.8, \quad 3$ df, $p=0.19 ; \quad$ Natrix- $\chi^{2}=2.2,3 \mathrm{df}$, $p=0.54)$.

\subsubsection{Prediction 8: more mobile species experience} higher overall rates of mortality than do sedentary species

One of the strongest impressions that we have obtained from this study is that species differ in their vulnerability. In particular, the sedentary aspic viper is the most abundant snake in the study area (based on capture and observation of live animals) and yet is rarely encountered as roadkills. Unfortunately, because $V$. aspis is also rarely captured under concrete slabs, we cannot quantify this difference. The only strong comparison is among the three species commonly found in the forest of Chizé over the period (1996 to 1998) when we intensively monitored the slabs. The number of road-killed animals was higher for Coluber $(N=118)$ than for Elaphe $(N=53)$, whereas the sample of live snakes contained more Elaphe $(N=101)$ than Coluber $(N=61)$. Natrix was the least abundant taxon in both samples $(N=13$ and $N=23$, respectively). Thus, the three species showed different relative abundances in the samples of live vs dead snakes $\left(\chi^{2}=35.9,2 \mathrm{df}\right.$, $p<0.0001)$; as predicted, the most mobile taxon (Coluber) was over-represented in the roadkills.

\subsubsection{Prediction 9: body size does not influence the risk of mortality in adult females}

We base this prediction on the fact that body size should not influence the distance that a female must migrate for egg-laying (in oviparous species) or the duration of gestation (in viviparous species). One-factor ANOVAs to compare body sizes of dead vs live adult females revealed no significant difference in either of the two species for which sufficient samples were available to carry out this test (Coluber viridiflavus - mean SVLs $=83.5 \mathrm{~cm}$ for living, $84.7 \mathrm{~cm}$ for dead, $F_{1,102}=0.35, \quad p=0.55 ; \quad$ Elaphe longissima-mean SVLs $=82.5 \mathrm{~cm}$ for living, $82.7 \mathrm{~cm}$ for dead; $F_{1,63}=0.011, p=0.92$ ).

\subsubsection{Prediction 10: body size may influence the risk of mortality in adult males}

Because previous work on snakes has suggested that larger males may move more extensively during the mating season (e.g. Shine, 1987; Bonnet and Naulleau, 1996a), we predicted that the roadkilled adult males may be larger on average than the living males we captured. This prediction was strongly supported for Elaphe longissima (mean SVLs=96.6 vs $86.8 \mathrm{~cm}$, $\left.F_{1,105}=13.27, p<0.001\right)$ but not for Coluber viridiflavus (mean SVLs=92.5 vs $95.1 \mathrm{~cm}, F_{1,194}=1.95$, $p=0.16)$. 


\section{Discussion}

The primary result from our analysis is that major patterns in the vulnerability of snakes to "predation" (including roadkills) can be predicted successfully from a simple hypothesis: the idea that snakes are most at risk when they travel outside their normal home range (Table 6). Within a species, mortality from this source is highest in the age/sex classes that disperse furthest, and at the times that the dispersal occurs (notably adult males in the mating season; neonates/hatchlings immediately after birth/hatching; and adult females on egglaying migrations). We do not doubt that other factors contribute to vulnerability as well; for example, large venomous species may be relatively invulnerable to many types of predators. However, our study strongly suggests that the extent of a snake's movements comprises one of the most important determinants of the risk that it experiences (Table 6). This conclusion will not be surprising to most herpetologists, but we are not aware of any previous attempt to test the hypothesis.

General patterns of mortality were similar in roadkilled snakes as in those taken by "natural" predators (Fig. 1). The two "predation" processes are certainly not identical: for example, larger body size may reduce a snake's vulnerability to a raptorial bird, but not to a truck. Both types of processes are important. Information on "natural" predation may help us to understand the selective forces that have shaped the evolution of life-history phenomena such as energy allocation "strategies" (e.g. Schaffer, 1974; Charnov, 1982). In particular, our data provide strong empirical support for the existence of significant mortality "costs of reproduction". In contrast, information on roadkills can help us to interpret current population structure and demography. Data on roadkills may also be of value in conservation planning, because it provides direct insight into the degree to which anthropogenic mortality decreases the population's reproductive output. It is logistically difficult to measure the relative impact of predation on any vertebrate population; indeed, it is probably impossible for most. Inevitably, then, a descriptive study such as ours must rely on a series of assumptions. Some of these assumptions include:

1. The sample of snakes collected under shelter items provides an unbiased sample of overall population structure. Undoubtedly, this is not strictly true: for example, seasonal and reproductive factors will influence the thermoregulatory benefits of using different kinds of retreat sites (Huey et al., 1989; Webb and Shine, 1998). However, this bias is likely to be minor compared to the strong biases associated with mortality risk (Table 3 ).

2. Even if we have correctly identified a strong association between dispersal and risk, it may not reflect any causal connection. For example, males may die during the mating period not because they move, but because they are less vigilant at this time. Any correlational data set can be challenged on this ground: all we point out is that dispersal is the single common feature of the high-risk phase in each of the population segments. The interspecific differences in seasonal timing of reproductive events means that abiotic correlates of mortality (due to similar weather conditions) can be discounted also.

Our data indicate that the degree of risk experienced by snakes varies among species, among seasons, among age and sex classes within species, and even among size classes within a single category of snake within a single season. The significantly higher mean body size of adult male Elaphe killed on the roads vs captured under shelter items suggests that larger males may move more widely. Although our data on Coluber revealed no such

Table 6

Summary of the main results from our study ${ }^{a}$

\begin{tabular}{|c|c|c|c|c|c|}
\hline Accidental mortality: Predictions & Combined $^{\mathrm{c}}$ & Coluber & Elaphe & Natrix & Vipera \\
\hline 1. Neonates experience high mortality & $* * \mathrm{~b}$ & $* *$ & - & $* *$ & - \\
\hline 2. Neonates killed during post hatchling dispersal & $* *$ & $* *$ & $* *$ & + & - \\
\hline 3. Subadult mortality low & $* *$ & $* *$ & $* *$ & $* *$ & - \\
\hline 4. Subadult mortality non-seasonal & + & + & + & + & + \\
\hline 5. Adult male mortality very high & $* *$ & $* *$ & $* *$ & No & $*$ \\
\hline 6. Male mortality peaks during the mating period & $* *$ & $* *$ & $* *$ & - & - \\
\hline 7. Oviparous females are killed during the laying period & $* *$ & $* *$ & $* *$ & $* *$ & ND \\
\hline 8. Active foragers more exposed than sit and wait & $* *$ & + & + & + & + \\
\hline 9. Body size does not influence mortality in adult females & ND & + & + & ND & ND \\
\hline 10. Body size may influence male mortality & ND & - & $* *$ & ND & ND \\
\hline
\end{tabular}

a The data are consistent with most of our predictions from the "dispersal vulnerability" hypothesis (see Table 2 for a list of these predictions).

b The table shows whether the data provide statistically significant support $(* *)$; the predicted trend but without statistical significance $(+)$; no clear trend (-); disagreement with statistical support (No); or insufficient data to perform the test (ND).

c "Combined" shows patterns from the pooled data. 
size bias, a similar study on this species, using a more geographically restricted set of comparisons, showed the same pattern in this taxon as well (Bonnet and Naulleau, 1996a).

In the particular study system that we used, several results have direct implications for conservation planning. These include:

1. The number of road-killed snakes provides a very poor indicator of actual abundances of different taxa; more mobile species may be greatly overrepresented among roadkills. Hence, roadkill counts should not be used to quantify relative abundances of taxa for conservation planning.

2. Intense mortality is typically concentrated over relatively brief periods of time, coinciding with the seasonal occurrence of activities such as matesearching or migrations to egg-laying sites. Thus, actions to ameliorate roadkill mortality (such as temporary road closures or speed restrictions) may need to function only briefly to be effective.

3. For sedentary species (such as the aspic viper in our study), direct anthropogenic mortality is likely to constitute only a trivial threat to population viability. For other taxa (such as Coluber), the impact may be substantial.

4. In terms of ecological impact, the most significant mortality is that involving females of oviparous species on their egg-laying migrations. Loss of these animals may substantially reduce the overall reproductive output of the entire population, whereas loss of the same number of adult males or neonates is likely to be less significant in this respect.

5. Fortunately, the egg-laying migrations are predictable in space as well as in time. Unlike matesearching males, the egg-laying females use relatively narrow migration corridors that are usually consistent among years and among females (pers. obs.). This predictability enhances the feasibility of management strategies to protect the migrating females. A similar situation occurs with seasonal migrations of pond-breeding amphibians, and management policies are well-developed for some such cases (e.g. Banks et al., 1994).

6. It may be possible to reduce the distances travelled in egg-laying migrations (and thus, reduce the mortality of this important component of the population) by providing appropriate egg-laying habitat close to high-density populations. The habitats used for egg-laying are often distinctive (e.g. Madsen, 1984; Hecnar, 1994) and can be created artificially with considerable success (Zuiderwijk et al., 1993; Collins and Swallow, 1995).

7. The magnitude of risk experienced by a reproducing female may depend upon reproductive mode.
Although evolutionary models posit that the phylogenetic transition from oviparity to viviparity involves higher "costs" and additional risks (e.g. Tinkle and Gibbons, 1977; Shine, 1985), vulnerability to anthropogenic mortality may actually be higher in the egg-layers (because of the need for a risky egg-laying migration).

The paucity of quantitative information on sources of mortality in snakes (e.g. Rosen and Lowe, 1994) or even, determinants of movement patterns (see Gregory et al., 1987; Gibbons and Sen-ditsch, 1987, for reviews) makes it difficult to assess the generality of the trends that we have detected within our study species. Comparisons with other kinds of animals are even more difficult, because logistical difficulties in quantifying predation rates within and among species have generally precluded such studies. Our work is encouraging in this respect, because it suggests that major patterns in "predation"-induced mortality may be predictable from simple hypotheses. Although the risk factors involved will differ among taxa, dispersal may be important in many cases (e.g. see Daly et al., 1990; Norrdahl and Korpimaki, 1998, for examples with small mammals). Workers familiar with other groups of animals may well be able to identify other, equally strong correlates of predation rates. In such cases, we can then use these correlated (and hopefully, more easily quantifiable) factors as surrogates for vulnerability, to facilitate predictions concerning the impact of anthropogenically-based mortality on natural populations.

\section{Acknowledgements}

The authors thank the small army who helped to collect snakes: O. Chastel, C. Clement, D. Guerineau, C. Notebaert, the very efficient and large Buzzard-team, Noune family, L. Blub, C. Thiburce, the Bilous, the Guillons, D. Lucchini, P. Duncan, C. Mauget, N. Maboul, X. Fichet, Y. Cherel, L. Jouventin, D. Barre, H.P. Eckstein, G. Baty, S. Houte, C. Attie, M.P. Vignault, E. Chamarre, E. Cabon, O. Lourdais, P. and R. Brillant, C. MacArthur, A. Moreau, N. Mabon, F. Jiguet, V. Garcia, M.P. Colace, P. Lys, J.C. Papot, A. Penloup, L. Pastout, H. Lormee, A. Aubeneau, T. Micol, P. Turcat, T. Picot, C. Caillot, C. Guinet, J.P. Baron, A. Pasquier, J. Burger, A. Lacroix, C. Rabouam, F. Lagarde, Y. Besson and many others, and the French ministry of environment for official authorisation. The Office National des Forets provided permits to collect wild animals in the Forest of Chize. Financial support was provided by the Centre National de la Recherche Scientifique (France) and the Australian Research Council. We hesitate to thank the many hitand-run drivers for help with data collection. 


\section{References}

Aldridge, R.D., Brown, W.S., 1995. Male reproductive cycle, age at maturity, and cost of reproduction in the timber rattlesnake (Crotalus horridus). Journal of Herpetology 29, 399-407.

Banks, B., Beebee, T.J.C., Cooke, A.S., 1994. Conservation of the natterjack toad (Bufo calamita) in Britain over the period 1970-1990 in relation to site protection and other factors. Biological Conservation $67,111-118$.

Bonnet, X., Naulleau, C., 1996a. Are body reserves important for reproduction in male dark green snakes (Colubridae: Coluber viridiflavus)? Herpetologica 52, 137-146.

Bonnet, X., Naulleau, G., 1996b. Catchability in snakes: consequences on breeding frequency estimates. Canadian Journal of Zoology 74, 233-239.

Bonnet, X., Naulleau, G., Mauget, R., 1994. The influence of body condition on $17-\beta$ estradiol levels in relation to vitellogenesis in female Vivera aspis (Reptilia, Viperidae). General and Comparative Endocrinology 93, 424-437.

Brown, W.S., 1993. Biology, status and management of the timber rattlesnake (Crotalus horridus): a guide for conservation. Herpetological Circulars 22, 1-78.

Burbidge, A.A., Jenkins, R.W.G., 1984. Endangered Vertebrates of Australia and its Island Territories. Report of the Working Group on Endangered Fauna of the Standing Committee of the Council of Nature Conservation Ministers. ACT, Canberra.

Castanet, J., Guyetant, R., 1989. Atlas de la Repartition des Amphibians et Reptiles de France. Société Herpétologique de France, Paris.

Caughley, G., Sinclair, A.R.E., 1994. Wildlife Ecology and Management. Blackwell Scientific, Boston, MA.

Charnov, E.L., 1982. The Theory of Sex Allocation. Princeton University Press, Princeton, NJ.

Ciofi, C., Chelazzi, G., 1991. Radiotracking of Coluber viridiflavus using external transmitters. Journal of Herpetology 25, 37-40.

Collins, A.M., Swallow, J.G., 1995. Artificial egg-laying sites for lizards: a conservation strategy. Biological Conservation 72, 387391.

Daly, M., Wilson, M., Behrends, P.R., Jacobs, L.R., 1990. Characteristics of kangaroo rats, Dipodomus merriami, associated with differential predation risk. Animal Behaviour 40, 380-389.

Dodd, C.K., 1987. Status, conservation, and management. In: Seigel, R.A., Collins, J.T., Novak, S.S. (Eds.), Snakes: Ecology and Evolutionary Biology. MacMillan, New York, pp. 478-513.

Dodd, C.K.J., 1993. Strategies for snake conservation. In: Seigel, R.A., Collins, J.T. (Eds.), Snakes. Ecology and Behavior. McGrawHill, New York, pp. 363-394.

Duguy, R., Saint Cirons, H., 1966. Cycle annuel et reproduction de la couleuvre vipérine. Terre et Vie 4, 423-457.

Eckstein, P.H., 1993. Untersuchungen zur Okologie des Ringelnatter (Natrix natrix Linneus 1758) Jahrbuch für Feldherpetologie, Beiheft.

Ehmann, H., Cogger, H., 1985. Australia's endangered herpetofauna: a review of criteria and policies. In: Grigg, G., Shine, R., Ehmann, H. (Eds.), The Biology of Australasian Frogs and Reptiles. Royal Zoological Society of New South Wales, Sydney, Australia, pp. 435-447.

Fitzgerald, L.A., Chani, J.M., Donadio, O.E., 1991. Tupinambis lizards in Argentina: implementing management of a traditionally exploited resource. In: Robinson, J., Redford, K. (Eds.), Neotropical Wildlife: Use and Conservation. University of Chicago Press, Chicago, IL, pp. 303-316.

Fitzgerald, L.A., Cruz, F.B., Perotti, G., 1993. The reproductive cycle and the size at maturity of Tupinambis rufescens (Sauria: Tefidae) in the dry Chaco of Argentina. Journal of Herpetology 27, 70-78.

Forsmann, A., 1995. Opposing fitness consequences of colour pattern in male and female snakes. Journal of Evolutionary Biology 8, 5370.

Gasc, J.P., Cabela, A., Crnobrnja-Isailovic, J., Dolmen, D., Grossenbacher, K, Haffner, P., Lescure, J., Martens, H., Martinez Rica, J.P., Maurin, H., Oliveira, M.E., Sofianidou, T.S., Veith, M., Zuiderwijk, A., 1995. Atlas of Amphibians and Reptiles in Europe. Europeae Herpetologica Muséum National d'Histoire Naturelle, Paris.

Gibbons, J.W., Semlitsch, R.D., 1987. Activity patterns. In: Seigel,
R.A., Collins, J.T., Novak, S.S. (Eds.), Snakes: Ecology and Evolutionary Biology. Macmillan, New York, pp. 396-421.

Gregory, P.T., Stewart, K.W., 1975. Long-distance dispersal and feeding strategy of the red-sided garter snake (Thamnophis sirtalis parietalis) in the Interlake of Manitoba. Canadian Journal of Zoology 53, 238-245.

Gregory, P.T., Macartney, J.M., Larsen, K.W., 1987. Spatial patterns and movements. In: Seigel, R.A., Collins, J.T., Novak, S.S. (Eds.), Snakes: Ecology and Evolutionary Biology. McGraw-Hill, New York, pp. 366-395.

Gruschwitz, M., Vokl, W., Kornacker, P.M., Waitzmann, M., Podloucky, R., Fritz, K., Gunther, R., 1993. Die schlangen Deutschlands-verbreitung und bestandssituation in den einzelnen Bundeslandern. Mertensiella 3, 7-38.

Hailey, A., Davies, P.M.C., 1986a. Diet and foraging behaviour of Natrix maura. Herpetological Journal 1, 53-61.

Hailey, A., Davies, P.M.C., 1986b. Lifestyle, latitude and activity metabolism of natricine snakes. Journal of Zoology 209, 461-476.

Hecnar, S.J., 1994. Nest distribution, site selection, and brooding in the five-lined skink (Eumeces fasciatus). Canadian Journal of Zoology $72,1510-1516$.

Huey, R.B., Peterson, C.R., Arnold, S.J., Porter, W.P., 1989. Hot rocks and not-so-hot rocks: retreat-site selection by garter snakes and its thermal consequences. Ecology 70, 931-944.

Klemens, M.W, Thorbjarnarson, J.B., 1995. Reptiles as a food resource. Biodiversity and Conservation 4, 281-298.

Luiselli, L., Capula, M., Shine, R., 1997. Food habits, growth rates, and reproductive biology of grass snakes, Natrix natrix (Colubridae) in the Italian Alps. Journal of Zoology 241, 371-380.

Madsen, T., 1984. Movements, home range size and habitat use of radio-tracked grass snakes (Natrix natrix) in southern Sweden. Copeia 1984, 707-713.

Madsen, T., 1987. Cost of reproduction and female life-history tactics in a population of grass snakes, Natrix natrix, in southern Sweden. Oikos 49, 129-132.

Madsen, T., Shine, R., 1992. Determinants of reproductive success in female adders, Vipera berus. Oecologia 92, 40-47.

Madsen, T., Shine, R., 1993. Costs of reproduction in a population of European adders. Oecologia 94, 488-495.

Madsen, T., Shine, R., 1994. Costs of reproduction influence the evolution of sexual size dimorphism in snakes. Evolution 48, 1389-1397.

Mittermeier, R.A., Carr, J.L., Swingland, I.R., Werner, T.B., Mast, R.B., 1992. Conservation of amphibians and reptiles. In: Adler, K. (Ed.), Herpetology. Current Research on the Biology of Amphibians and Reptiles. Society for the Study of Amphibians and Reptiles, Oxford, OH, pp. 59-80.

Naulleau, G., 1965. La biologie et le comportement prédateur de Vipera aspis au laboratoire et dans la nature. Bulletin Biologique de la France et de la Belgique 99, 395-524.

Naulleau, G., 1989. Etude biotélémetrique des déplacements et de la temperature chez la couleuvre d'Esculape Elaphe longissima (Squamata, Colubridae) en zone forestière. Bulletin de la Société Herpétologique de France 52, 45-53.

Naulleau, G., 1992. Reproduction de la couleuvre d'Esculape Elaphe longissima Laurenti (Reptilia, Colubridae) dans le centre ouest de la France. Bulletin de la Société Herpétologique de France 62, 9-17.

Naulleau, G., Saint Girons, H., 1981. Poids des nouveau-nés et reproduction de Vipera aspis (Reptilia: Viperidae), dans des conditions naturelles et artificielles. Amphibia-Reptilia 2, 51-62.

Naulleau, G., Bonnet, X., 1995. Reproductive ecology, body fat reserves and foraging mode of two contrasted snakes species: Vipera aspis (terrestrial, viviparous) and Elaphe longissima (semi-arboreal, oviparous). Amphibia-Reptilia 16, 37-460.

Naulleau, G., Verheyden, C., Bonnet, X., 1997. Prédation spécialisée sur la vipére aspic Vipera aspis par un couple de buses variables Buteo buteo. Alauda 65, 155-160.

Norrdahl, K., Korpimaki, E., 1998. Does mobility or sex of voles affect risk of predation by mammalian predators? Ecology 79, 226-232.

Rosen, P.C., Lowe, C.H., 1994. Highway mortality of snakes in the Sonoran desert of southern Arizona. Biological Conservation 68, 143-148.

Saint Girons, H., 1957. Le cycle sexuel chez Vipera aspis (L) dans l'ouest de la France. Bulletin de Biologie de la France et la Belgique 91, 284-350. 
Saint Girons, H., 1975. Croissance et fécondité de Vipera aspis. Vie et Milieu 8, 265-286.

Saint Girons, H., 1986. Caractères ecophysiologiques du cycle sexuel des serpents dans, les régions tempérdes. In: Assenmacher, I., Boissin, J. (Eds.), Endocrine Regulations as Adaptive Mechanisms to the Environment. CNRS, Paris, pp. 63-77.

Schaffer, W.M., 1974. Optimal reproductive effort in fluctuating environments. American Naturalist 108, 783-900.

Seigel, R.A., 1986. Ecology and conservation of the massasauga (Sistrurus catenatus) in Missouri. Biological Conservation 35, 333-346.

Shine, R., 1985. The evolution of viviparity in reptiles: an ecological analysis. In: Gans, C., Billett, F. (Eds.), Biology of the Reptilia, vol. 15. John Wiley and Sons, New York, pp. 605-694.

Shine, R., 1987. Intraspecific variation in thermoregulation, movements and habitat use by Australian blacksnakes, Pseudechis porphyriacus (Elapidae). Journal of Herpetology 21, 165-177.

Shine, R., 1993. Ecological studies on Australian pythons. In: Uricheck, M. (Ed.), Proceedings of the Fifteenth International Herpetological Symposium. International Herpetological Symposium, Seattle, WA, pp. 29-40.

Shine, R., 1994. Sexual size dimorphism in snakes revisited. Copeia 1994, 326-346.
Shine, R., Fitzgerald, M., 1995. Variation in mating systems and sexual size dimorphism between populations of the Australian python Morelia spilota (Serpentes: Pythonidae). Oecologia 103, 490-498.

Slip, D.J., 1986. Ecology and Thermal Biology of the Diamond Python, Morelia spilota spilota. M.Sc. thesis, University of Sydney.

Tinkle, D.W., Gibbons, J.W., 1977. The distribution and evolution of viviparity in reptiles. Miscellaneous publications of the Museum of Zoology, University of Michigan, vol. 154, pp. 1-55.

Vacher, M., 1997. Comportement sexuel, condition corporelle et stratéagie de reproduction chez Vipera aspis: étude en milieu naturel. Unpubl. PhD. thesis, University François Rabelais, Tours, France.

Warwick, C., Steedman, C., Holford, T., 1991. Rattlesnake collection drives - their implications for species and environmental conservation. Oryx 25, 3944.

Webb, J.K., Shine, R., 1998. Using thermal ecology to predict retreatsite selection by an endangered snake species. Biological Conservation, In press.

Zuiderwijk, A., Smit, G., Van Den Bogert, H., 1993. Man-made hatcheries for grass snakes (Natrix natrix L. 1758): a simple method for grass snake conservation. Mertensiella 3, 227-234. 